\title{
Production of theophylline via aerobic fermentation of pu-erh tea using tea- derived fungi
}

\author{
Binxing Zhou ${ }^{1 * \dagger} \mathbb{D}$, Cunqiang Ma, ${ }^{1,2 \dagger}$, Xiaoying Ren ${ }^{1,3}$, Tao Xia ${ }^{4}$, Xiaohong $\mathrm{Li}^{1}$ and Yang $\mathrm{Wu}^{1}$
}

\begin{abstract}
Background: Caffeine is one of the most abundant methylxanthines in tea, and it remains stable in processing of general teas. In the secondary metabolism of microorganism, theophylline is the main conversion product in caffeine catabolism through demethylation. Microorganisms, involved in the solid-state fermentation of pu-erh tea, have a certain impact on caffeine level. Inoculating an appropriate starter strain that is able to convert caffeine to theophylline would be an alternative way to obtain theophylline in tea. The purpose of this study was to isolate and identify the effective strain converting caffeine to theophylline in pu-erh tea, and discuss the optimal conditions for theophylline production.

Results: Caffeine content was decreased significantly $(p<0.05)$ and theophylline content was increased significantly $(p<0.05)$ during the aerobic fermentation of pu-erh tea. Five dominant fungi were isolated from the aerobic fermentation and identified as Aspergillus niger, Aspergillus sydowii, Aspergillus pallidofulvus, Aspergillus sesamicola and Penicillium mangini, respectively. Especially, A. pallidofulvus, A. sesamicola and P. mangini were detected in pu-erh tea for the first time. All isolates except $A$. sydowii TET-2, enhanced caffeine content and had no significant influence on theophylline content. In the aerobic fermentation of A. sydowii TET-2, $28.8 \mathrm{mg} / \mathrm{g}$ of caffeine was degraded, $93.18 \%$ of degraded caffeine was converted to theophylline, and $24.60 \mathrm{mg} / \mathrm{g}$ of theophylline was produced. A. sydowii PET-2 could convert caffeine to theophylline significantly, and had application potential in the production of theophylline. The optimum conditions of theophylline production in the aerobic fermentation were 1) initial moisture content of $35 \%(\mathrm{w} / \mathrm{w}), 2)$ inoculation quantity of $8 \%$, and 3 ) incubation temperature at $35^{\circ} \mathrm{C}$.

Conclusions: For the first time, we find that A. sydowii PET-2 could convert caffeine to theophylline, and has the potential value in theophylline production through aerobic fermentation.
\end{abstract}

Keywords: Pu-erh tea, Aerobic fermentation, Fungi, Caffeine, Theophylline

\section{Background}

Methylxanthines are natural and synthetic compounds found in many foods, drinks, pharmaceuticals, and cosmetics [1]. Caffeine (1, 3, 7-trimethylxanthine or 3, 7dihydro-1, 3, 7-trimethyl-1H-2, 6dione) is one of the most abundant methylxanthines in tea, it counts $30-50 \mathrm{mg} / \mathrm{g}$ of dry matter weight. Several bacteria and fungi have been selected from the soil of tea and coffee plantations to degrade caffeine. The bacteria which have capability of degrading

\footnotetext{
*Correspondence: bxzhou01@126.com

${ }^{\dagger}$ Binxing Zhou and Cunqiang Ma contributed equally to this work.

${ }^{1}$ College of Long Run Pu-erh Tea, Yunnan Agricultural University, Kunming 650201, Yunnan, People's Republic of China

Full list of author information is available at the end of the article
}

caffeine are mainly including Pseudomonas putida [2, 3], Pseudomonas lutea [4] and Serratia marcescens [5]. Caffeine-degrading fungi [6, 7] are Aspergillus tamarii, Fusarium solani, Aspergillus niger and Penicillium commune. In the secondary metabolism of microorganisms, both demethylation and oxidation are found in caffeine degradation, and demethylation is the main caffeine degradation pathway [2]. However, under the effect of caffeinedegrading fungi, theophylline (1, 3-dimethyxanthine) is the major metabolite of caffeine [3], and it is different from the metabolites in bacteria [8].

Caffeine level remains stable in the processing of general teas (green tea, black tea, oolong tea and white tea) $[9,10]$. Tea cultivar is the only factor could impact caffeine content

(c) The Author(s). 2019 Open Access This article is distributed under the terms of the Creative Commons Attribution 4.0 International License (http://creativecommons.org/licenses/by/4.0/), which permits unrestricted use, distribution, and 
in fresh tea leaves [11]. Pu-erh tea (pu-erh shucha) is produced through a natural solid-state fermentation process by using the sun-dried green tea leaves (Camellia sinensis var. assamica (JW Masters) Kitamura) as the raw material [1214]. Caffeine content is changing in pu-erh tea, which should be attributed to the participation of microorganisms found in the solid-state fermentation [15-18]. Some reports found that several microorganisms such as Candida albicans, Candida famata (Debaryomyces hansenii), Aspergillus niger and Aspergillus sydowii have potential capability to reduce caffeine content through an inoculated fermentation [18-20]. This suggests that the effective strain with the capability of converting caffeine to theophylline could be found in pu-erh tea.

Theophylline is a common prescribed drug for treatment of asthma and chronic obstructive pulmonary disease (COPD) through bronchodilator and anti-inflammatory effects on the respiratory system [21]. In addition, theophylline can be used as an initial treatment in asthma attacks and other clinical conditions, together with $\beta 2$-mimetic drugs and corticosteroids [22]. During the caffeine catabolism of tea tree (Camellia sinesis (L.) O. Kuntze), theophylline is a transient metabolite and stays at a very low level as one of natural methylxanthines [23]. Hence, inoculation of an effective strain/ effective strains during the fermentation of tea leaves is an alternative way to produce theophylline.

In this paper, five fungal strains were isolated from the aerobic fermentation of pu-erh tea and identified as $A$. niger, A. sydowii, Aspergillus pallidofulvus, Aspergillus sesamicola and Penicillium mangini, respectively. A. sydowii PET-2 could convert caffeine to theophylline, which had a potential value in theophylline production. In addition, the optimal conditions for caffeine degradation and theophylline production were discussed.

\section{Results}

Differences between aerobic and anaerobic fermentation In a previous study [20], caffeine content was decreased significantly $(p<0.05)$ during the solid-state fermentation of pu-erh tea. Aerobic and anaerobic fermentation was carried out at a natural condition to simulate the solid-state fermentation of pu-erh tea. Fungi count, caffeine and theophylline contents were determined in the fermentation. Results are presented in Fig. 1. There were significant $(p<0.05)$ differences in fungi count, caffeine and theophylline contents between aerobic and anaerobic fermentation. Compared with the anaerobic fermentation, caffeine content was decreased significantly $(p<0.05)$ in the aerobic fermentation; about $16.73 \mathrm{mg} / \mathrm{g}$ of caffeine of dry matter weight of tea leaves was degraded at the end of the fermentation. Furthermore, theophylline content was increased significantly $(p<$ $0.05)$ along with caffeine degradation and about 15.52 $\mathrm{mg} / \mathrm{g}$ of theophylline was produced at the end of the fermentation. As shown in Fig. 1A, fungal colony count increased dramatically from day 0 to day 6 and maintained at a high level during the whole fermentation. The microbial metabolism in aerobic fermentation was more active than anaerobic fermentation. Based on the changes of caffeine and theophylline contents, we predicted that the fungi in the aerobic fermentation lead to the conversion of caffeine to theophylline. Therefore, samples collected from the aerobic fermentation were used to isolate potential starter strains and the dominant fungi were analyzed in this paper.

\section{Identification results of fungi in aerobic fermentation}

A total of 5 fungal strains were isolated from the aerobic fermentation of pu-erh tea. The received sequence (546 bp) of PET-1 is provided in Additional file 1: Fig. S1. The received sequence $(516 \mathrm{bp}$ ) of PET-2 is provided in Additional file 1: Fig. S2. The received sequences (541 bp ITS sequence, $516 \mathrm{bp} \beta$-Tubulin sequence and $765 \mathrm{bp} \mathrm{Cal-}$ modulin sequence, respectively) of PET-3 are provided in Additional file 1: Fig. S3. The received sequences (532 bp ITS sequence, $515 \mathrm{bp} \beta$-Tubulin sequence and $757 \mathrm{bp} \mathrm{Cal-}$ modulin sequence, respectively) of PET- 4 are provided in Additional file 1: Fig. S4. The received sequences ( $525 \mathrm{bp}$ ITS sequence and $420 \mathrm{bp} \beta$-Tubulin sequence, respectively) of PET-5 are provided in Additional file 1: Fig. S5. After the molecular identification, 5 fungal strains were identified as $A$. niger $(99.8 \%$ sequence identity with strain NCBT1 10A), A. sydowii $(99.8 \%$ sequence identity with strain NRRL250), A. pallidofulvus (99.9\% sequence identity with strain NRRL4789), A. sesamicola ( $99.8 \%$ sequence identity with strain CBS137324) and $P$. mangini (99.6\% sequence identity with strain CBS253.31), respectively (Table 1). As shown in Fig. 2, all fungal strains were detected at various stages in the aerobic fermentation. The isolated fungi account for $86.67-97.14 \%$ in total colony count from day 3 to day 15 , which could be considered as the dominant fungi in the fermentation.

\section{Effects of microorganisms on the conversion of caffeine to theophylline}

In order to find out the effects of microorganisms on the conversion of caffeine to theophylline, the isolated fungal strains were inoculated into the sun-dried tea leaves and cultivated in the incubator at $30^{\circ} \mathrm{C}$ for the aerobic fermentation, respectively. As shown in Fig. 3, different microorganisms affected on caffeine and theophylline contents differently. Compared with the sterilization treatment, $A$. niger PET-1, A. pallidofulvus PET-3, A. sesamicola PET-4 and $P$. mangini PET-5 increased caffeine content significantly (Fig. 3a), which should be attributed to microbial metabolism and nutrient loss. However, there was no significant increase of theophylline content in the aerobic fermentation of $A$. niger PET-1, A. pallidofulvus PET-3, A. 

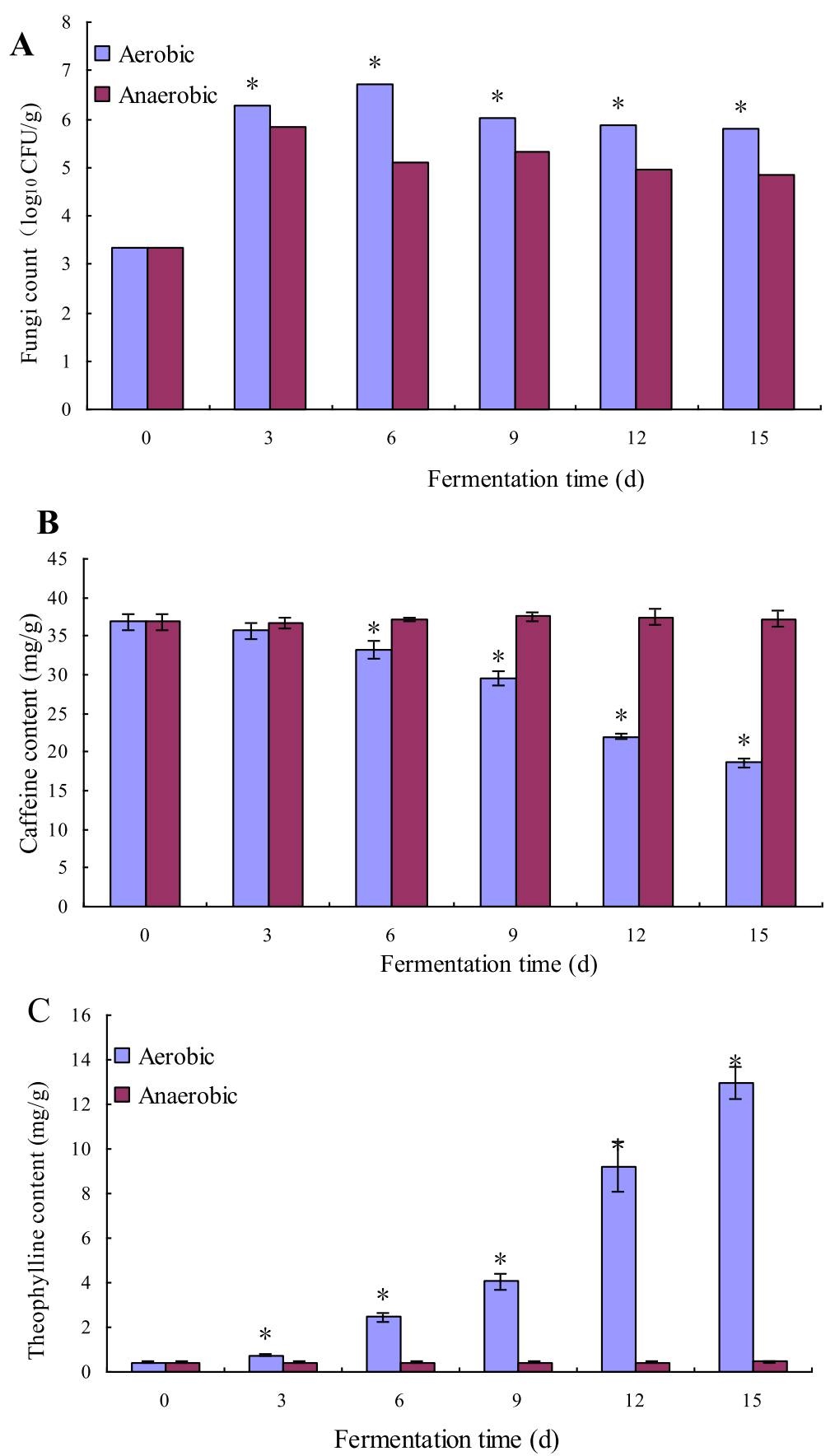

Fig. 1 Differences between aerobic and anaerobic fermentation in fungi count (a), caffeine $(\mathbf{b})$ and theophylline (c).Data are presented as mean value \pm SD of three independent tests. * indicated there is significant difference between aerobic and anaerobic fermentation (Duncan's multiple range test: $p<0.05$ )

sesamicola PET-4 and P. mangini PET-5, respectively (Fig. 3b). During the fermentation inoculated by $A$. sydowii PET2 , caffeine content was decreased significantly $(p<0.05)$ and theophylline content was increased significantly $(p<0.05)$ (Fig. 3). At the end of the fermentation (day 15), $28.85 \mathrm{mg} / \mathrm{g}$ of caffeine was degraded with an amplitude of about $86.80 \%$. With the degrading of caffeine, $24.60 \mathrm{mg} / \mathrm{g}$ of theophylline was produced at day 15 and became the main methylxanthine in the aerobic fermentation. Therefore, $A$. sydowii PET-2 had the capability of converting caffeine to theophylline,

\section{Ability of $A$. sydowii PET-2 converting caffeine to theophylline}

A. sydowii PET-2 was inoculated into the sun-dried tea leaves for the aerobic fermentation and the kinetic 
Table 1 Dominant fungi isolated from the aerobic fermentation of pu-erh tea and identified by sequence determination

\begin{tabular}{|c|c|c|c|c|c|c|}
\hline Strains & gene & Primers & Fragments (bp) & Species & Strain number & identity \\
\hline PET-1 & ITS & ITS1/ITS4 & 546 & Aspergillus niger & NCBT110A & $99.8 \%$ \\
\hline PET-2 & ITS & ITS1/ITS4 & 516 & Aspergillus sydowii & NRRL250 & $99.8 \%$ \\
\hline \multirow[t]{3}{*}{ PET-3 } & ITS & TS1/ITS4 & 541 & Aspergillus pallidofulvus & NRRL4789 & $99.9 \%$ \\
\hline & $\beta$-Tubulin & $\mathrm{Bt} 2 \mathrm{a} / \mathrm{Bt} 2 \mathrm{~b}$ & 516 & & & \\
\hline & Calmodulin & CF1L/CF4 & 765 & & & \\
\hline \multirow[t]{3}{*}{ PET-4 } & ITS & TS1/ITS4 & 532 & Aspergillus sesamicola & CBS 137324 & $99.8 \%$ \\
\hline & $\beta$-Tubulin & $\mathrm{Bt} 2 \mathrm{a} / \mathrm{Bt} 2 \mathrm{~b}$ & 515 & & & \\
\hline & Calmodulin & CF1L/CF4 & 757 & & & \\
\hline \multirow[t]{2}{*}{ PET-5 } & ITS & TS1/ITS4 & 525 & Penicillium manginii & CBS253.31 & $99.6 \%$ \\
\hline & $\beta$-Tubulin & Bt2a/Bt2b & 420 & & & \\
\hline
\end{tabular}

parameters were established to study the conversion of caffeine to theophylline. As the fermentation progressed, tea polyphenols, and the main tea pigments including theaflavins, thearubigins and theabrownins contents were measured. The results are provided in Additional file 2:Table S1. During the aerobic fermentation, tea polyphenols content was decreased significantly $(p<$ $0.05)$, theabrownins content was increased significantly $(p<0.05)$. Similar changes of tea polyphenols and theabrownins contents were found in the solid-sate fermentation of pu-erh tea. In the end of the fermentation, theabrownins content reached the national quality requirements of pu-erh tea. Therefore, A. sydowii PET-2 could be used in the pu-erh tea fermentation.

The kinetic parameters in the inoculated fermentation, including caffeine content $\left(C_{\text {caffeine, }}\right)$, theophylline content $\left(C_{\text {theophylline, }}\right)$, the yield of theophylline $\left(\mathrm{Y}_{\text {theophylline/caffeine }}\right)$, caffeine removal ratio (\%) and theophylline production $(\mathrm{mg} / \mathrm{g})$ are listed in Table 2. As shown in Table 2, approximately $7.25,15.52,34.47,63.93$, and $83.88 \%$ of caffeine were degraded at day 3, 6, 9, 12 and 15, respectively. Moreover, theophylline was detected and produced with the degrading of caffeine. At the end of the fermentation, $24.60 \pm 1.18 \mathrm{mg} / \mathrm{g}$ of theophylline was produced, the yield of theophylline stayed at $85 \%$, and about $93.18 \%$ of degraded caffeine was converted to theophylline. The production of theophylline was consistent with the tendency of caffeine degradation. A. sydowii PET-2 could lead caffeine degradation and convert most of the degraded caffeine to theophylline in the inoculated fermentation, which indicated that $A$. sydowii PET-2 had the most capability of converting caffeine to theophylline.

Due to the caffeine conversion characteristic, A. sydowii PET-2 had broad application prospects in the production of theophylline via an aerobic fermentation. The influence factors of theophylline production such as moisture content, inoculation quantity and incubation temperature were discussed later in this paper.

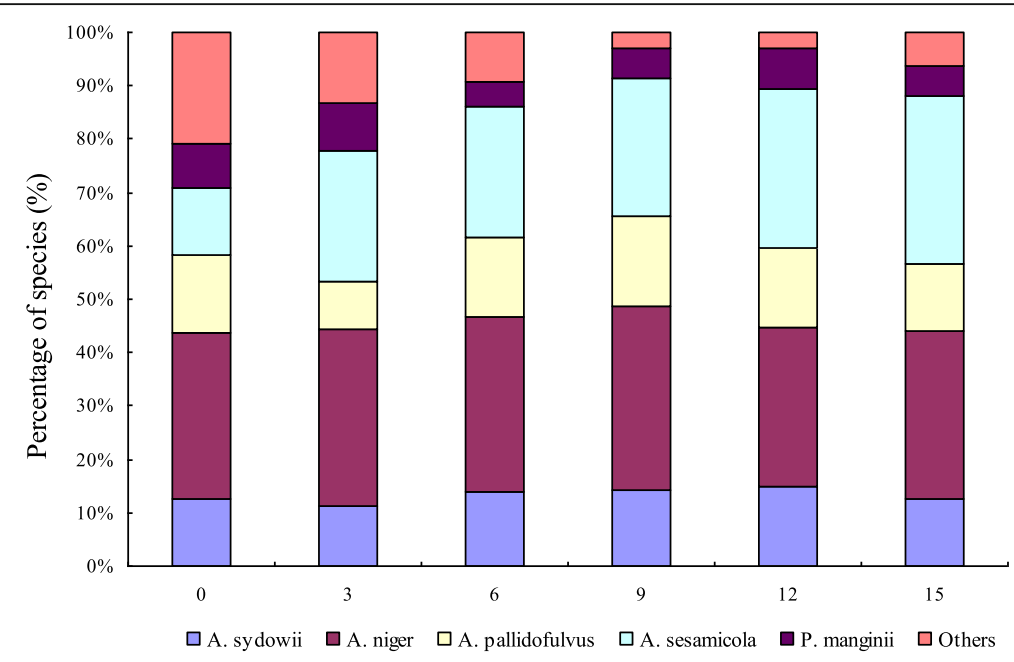

Fermentation time(d)

Fig. 2 Changes in distribution of dominant fungi during pu-erh tea aerobic fermentation 


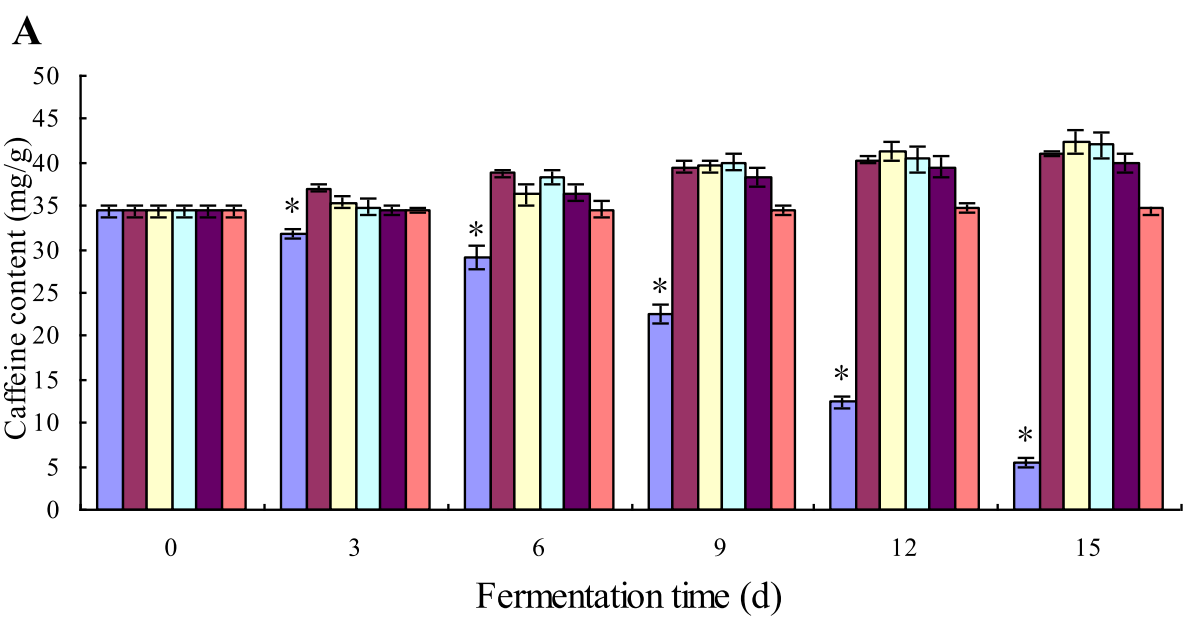

B

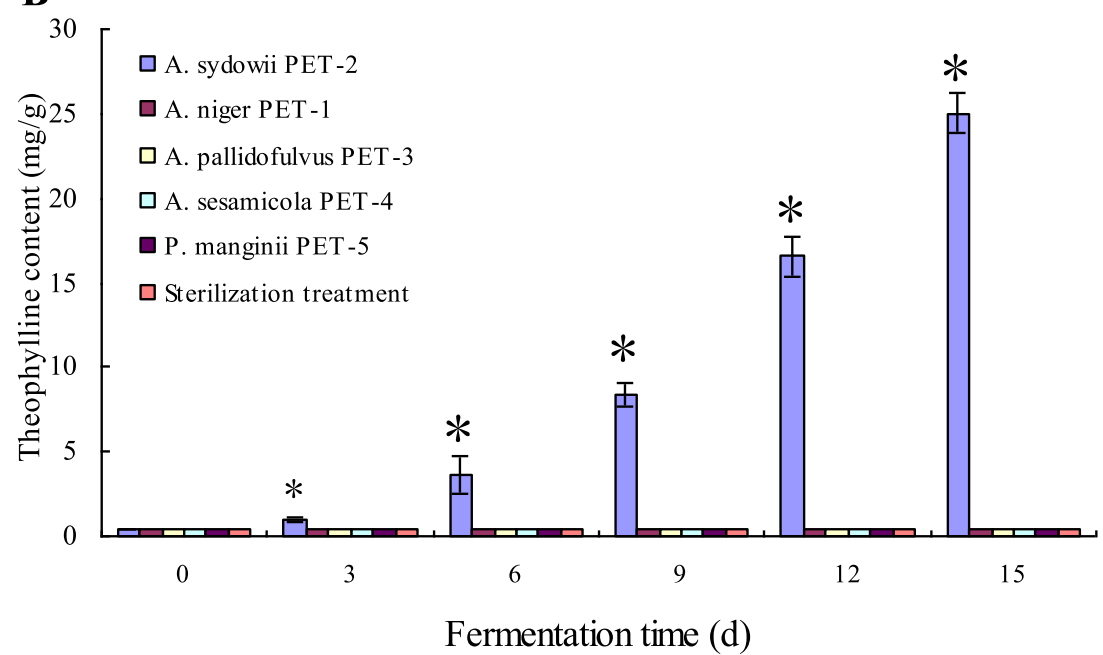

Fig. 3 Changes in contents of caffeine (a) and theophylline (b) in aerobic fermentation inoculated by tea-derived strains, and sterilization treatment group. Data are presented as mean value \pm SD of three replications. ${ }^{*}$ indicated there is significant difference $(p<0.05)$ between $A$. sydowii PET-2 fermentation group and other treatment groups according to Duncan's test

Table 2 Kinetic parameters for the conversion of caffeine to theophylline in the fermentation of A. sydowii PET-2

\begin{tabular}{llllll}
\hline Time (d) & $C_{\text {caffeine, }}(\mathrm{mg} / \mathrm{g})$ & $\begin{array}{l}C_{\text {theophylline,t }} \\
(\mathrm{mg} / \mathrm{g})\end{array}$ & $\begin{array}{l}Y \\
\text { theophylline/caffeine }\end{array}$ & Caffeine removal ratio (\%) & Theophylline production (mg/g) \\
\hline 0 & $34.39 \pm 0.69$ & $0.43 \pm 0.04$ & $\mathrm{ND}$ & $\mathrm{ND}$ & $\mathrm{ND}$ \\
3 & $31.89 \pm 0.51$ & $0.98 \pm 0.20$ & $0.23 \pm 0.09$ & $7.25 \pm 2.82$ & $0.55 \pm 0.19$ \\
6 & $29.05 \pm 1.45$ & $3.62 \pm 1.10$ & $0.59 \pm 0.10$ & $15.52 \pm 4.11$ & $3.19 \pm 1.08$ \\
9 & $22.54 \pm 1.00$ & $8.39 \pm 0.72$ & $0.67 \pm 0.08$ & $34.47 \pm 2.30$ & $7.96 \pm 0.69$ \\
12 & $12.40 \pm 0.76$ & $16.54 \pm 1.16$ & $0.73 \pm 0.06$ & $63.93 \pm 2.77$ & $16.11 \pm 1.15$ \\
15 & $5.54 \pm 0.55$ & $25.03 \pm 1.17$ & $0.85 \pm 0.03$ & $83.88 \pm 1.77$ & $24.60 \pm 1.18$ \\
\hline
\end{tabular}

All data are presented as mean value \pm SD of three replications, ND was not detected.

Contents of caffeine and theophylline were determined by HPLC.

Samples collected on 0 day were the raw material for the fermentation.

$C_{\text {caffeine,t }}$ was the caffeine content $(\mathrm{mg} / \mathrm{g})$ detected in the fermentation; $C_{\text {theophylline, }}$ was the theophylline content $(\mathrm{mg} / \mathrm{g})$ detected in the

fermentation; $Y_{\text {theophylline/caffeine }}=$ theophyline yield on caffeine $(\mathrm{mg} / \mathrm{mg})$. Caffeine removal ratio $(\%)=\left(C_{\text {caffeine }, 0}-C_{\text {caffeine, }, t}\right) / C_{\text {caffeine, }},{ }^{*} 100 \%$; Theophylline

production $(\mathrm{mg} / \mathrm{g})=C_{\text {theophylline, }}-C_{\text {theophylline, }, 0}$. 
Selection of optimal condition in moisture content with inoculation quantity of $4 \%$ and incubation temperature at $30^{\circ} \mathrm{C}$

A. sydowii PET-2 was inoculated into the sun-dried tea leaves with increasing initial moisture contents $(25,30$, 35,40 and $45 \%$, respectively) and cultivated in the incubator at the temperature of $30{ }^{\circ} \mathrm{C}$. Caffeine and theophylline contents were determined by HPLC during the fermentation. Caffeine removal ratio (\%) and theophylline production $(\mathrm{mg} / \mathrm{g})$ were calculated to investigate the influence of moisture content on caffeine conversion. As shown in Fig. 4, caffeine removal ratio and theophylline production increased steadily with the fermentation. The microbial metabolism was influenced by moisture content, thus moisture content had significant impacts on caffeine degradation and theophylline production. The experiments indicated that the fermentation group with the initial moisture content of $35 \%$ (w/w) had the highest caffeine removal ratio and theophylline production. In addition, caffeine removal ratio and theophylline production decreased significantly $(p<0.05)$ in lower moisture content. Only about $49.78 \%$ of caffeine was degraded and $13.34 \mathrm{mg} / \mathrm{g}$ of theophylline was produced in $25 \%(\mathrm{w} / \mathrm{w})$ of moisture content at day 15 . The single factor analysis showed that $35 \%(\mathrm{w} / \mathrm{w})$ was the appropriate initial moisture content for the conversion of caffeine to theophylline.

\section{Selection of optimal condition in inoculation quantity with initial moisture content of $35 \%(w / w)$ and incubation temperature at $30^{\circ} \mathrm{C}$}

A set of different inoculation quantities was built to find out the optimal inoculation quantity for caffeine conversion. Caffeine removal ratio (\%) and theophylline production $(\mathrm{mg} / \mathrm{g})$ were calculated and showed in Fig. 5. In low inoculation quantity (1\%), the caffeine conversion was inhibited, only about $51.54 \%$ of caffeine was degraded and $15.72 \mathrm{mg} / \mathrm{g}$ of theophylline was produced at day 15 . With the increasing inoculation quantity applied (from 1 to $8 \%$ ), the caffeine conversion capability increased obviously. However, in high inoculation level $(8,12$, and $16 \%$, respectively), there were no significant $(p>0.05)$ changes in caffeine removal ratio and theophylline production. Through comparison and analysis, $8 \%$ was the optimal inoculation quantity with the higher caffeine removal ratio and theophylline production.

\section{Selection of optimal condition in incubation temperature with initial moisture of $35 \%(w / w)$ and inoculation quantity of $4 \%$}

Incubation temperature had a significant impact on microbial metabolism. In order to compare the caffeine conversion level from caffeine to theophylline in different incubation temperatures, A. sydowii PET-2 was inoculated into the sun-dried tea leaves with an initial moisture content of $35 \%(\mathrm{w} / \mathrm{w})$ and an inoculation quantity of $4 \%$, and cultivated in the incubator with different incubation temperatures $\left(25,30,35,40\right.$ and $45^{\circ} \mathrm{C}$, respectively) for 15 days. Caffeine and theophylline contents were determined, and caffeine removal ratio (\%) and theophylline production $(\mathrm{mg} / \mathrm{g})$ are showed in Fig. 6. In the temperature range between 25 and $35^{\circ} \mathrm{C}$, caffeine removal ratio and theophylline production increased significantly $(p<0.05)$. Between 40 and $45^{\circ} \mathrm{C}$, because the growth and metabolism of microorganism were inhibited, caffeine removal ratio and theophylline production declined obviously. Therefore, $35^{\circ} \mathrm{C}$ was the optimal temperature for the conversion of caffeine to theophylline.

\section{Discussion}

$\mathrm{Pu}$-erh tea is one of the traditional Chinese teas. Based on the recent researches, pu-erh tea has a certain positive effect on human health, including reducing waist fat, increasing antioxidant capacity and antiinflammatory ability, and preventing atherosclerosis and cancer [24-26]. Due to the benefits in antidiabetics, hypolipidemic and antirheumatic [27-29], pu-erh tea has been produced and drank by the minority groups of the Yunnan people in China for centuries [30].

Solid-state fermentation is the key process in pu-erh tea, which includes aerobic fermentation in surface and anaerobic fermentation in centre [31]. The species within the genera Aspergillus, Penicillium, Rhizomucor, Mucor, Cladosporium and Eurotium are reported widely in pu-erh tea solid-state fermentation [32, 33]. Aspergillus spp. and Saccharomyces spp. were the main fungi in aerobic and anaerobic fermentation of pu-erh tea [30, 34]. A. niger, A. tamarii, Aspergillus tubingensis, Aspergillus fumigatus, Aspergillus acidus, Aspergillus awamori, Blastobotrys adeninivorans, Candida tropicalis, Fusarium graminearum, Millerozyma (syn. Pichia) farinosa, Rasamsonia byssochlamydoides, Rasamsonia emersonii, Rasamsonia cylindrospora, Rhizomucor pusillus, Rhizomucor tauricus, and Thermomyces lanuginosus have been detected in pu-erh tea [35-38]. In this study, 5 fungal strains were selected and identified as A. niger, A. sydowii, A. pallidofulvus, A. sesamicola and $P$. mangini from the aerobic fermentation of pu-erh tea, respectively.

Recently, A. niger has been reported widely and considered as the predominant fungi contributing to the fermentation and quality of pu-erh tea $[31,39,40]$. A. niger was detected in the aerobic fermentation of pu-erh tea and superior in the quantity, which conformed with the previous studies [32-34]. Other fungal species were rarely detected in pu-erh tea fermentation. Especially, $A$. pallidofulvus, A. sesamicola and P. mangini were found in pu-erh tea for the first time. 

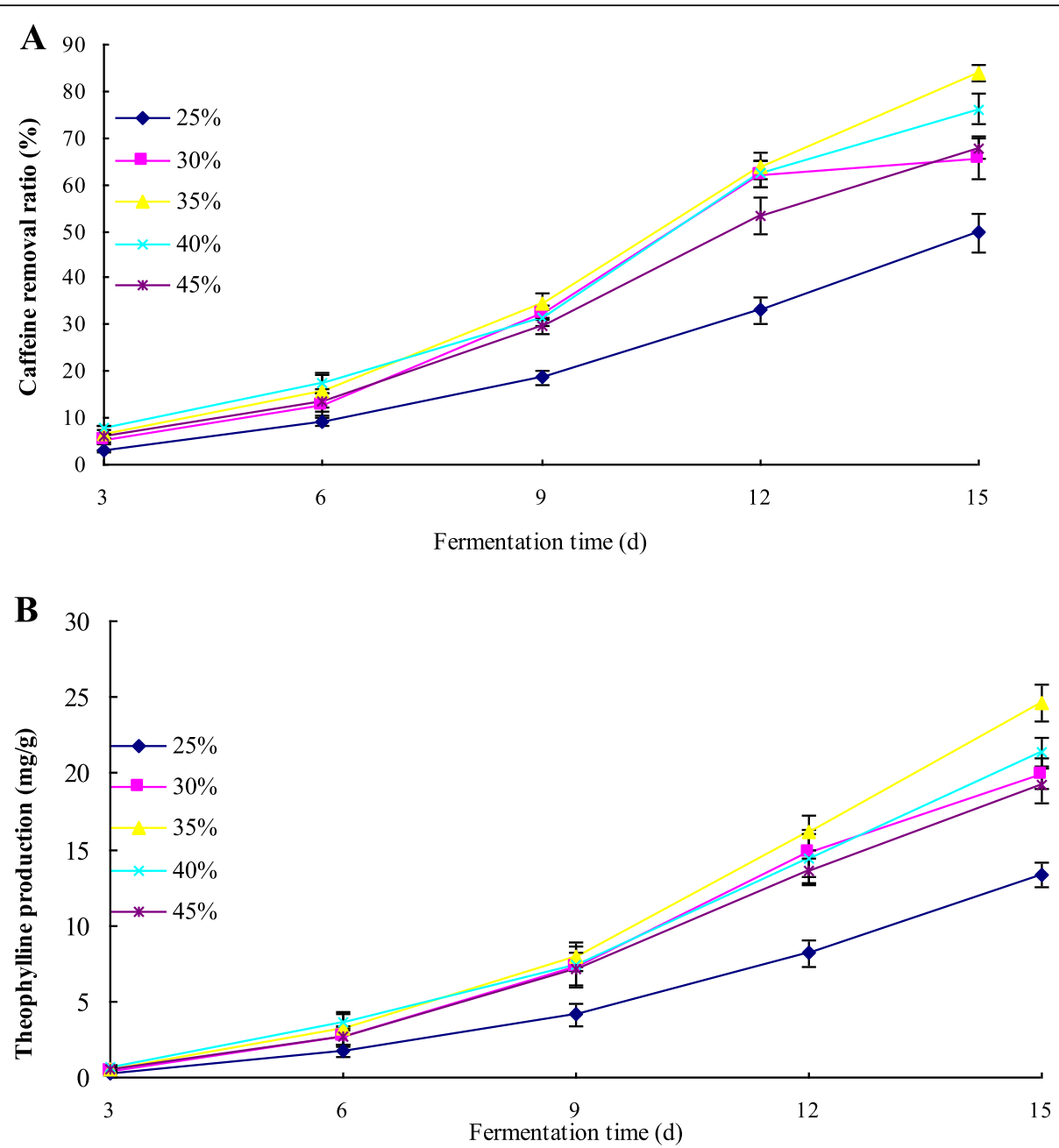

Fig. 4 Effect of moisture content in an aerobic fermentation inoculated by A. sydowii PET-2 on caffeine degradation (a) and theophylline production (b).Data are presented as mean value $\pm \mathrm{SD}$ of three replications. Caffeine removal ratio $=\left(\mathrm{C}_{\text {caffeine }, 0}-\mathrm{C}_{\text {caffeine,t }}\right) / \mathrm{C}_{\text {caffeine }, 0}{ }^{*} 100 \%$; Theophylline production $=C_{\text {theophylline, }}{ }^{-} C_{\text {theophylline, }, 0} \cdot C_{\text {caffeine, }, 0}$ was the initial caffeine content $(\mathrm{mg} / \mathrm{g}), C_{\text {caffeine,t }}$ was the caffeine content $(\mathrm{mg} / \mathrm{g})$ detected in the fermentation. $C_{\text {theophylline,t }}$ was the theophylline content $\left(\mathrm{mg} / \mathrm{g}\right.$ ) detected in the fermentation, $C_{\text {theophylline,o }}$ was the initial theophylline content (mg/g)

During the solid-state fermentation of pu-erh tea, fungi have significant impacts in chemical components and tea quality [41]. In the physiology of tea tree (Camellia sinesis (L.) O. Kuntze), theophylline is the transient metabolite in caffeine catabolism and stays at a very low level [23, 42]. Furthermore, the primarily metabolic pathway via caffeine-theophylline route in fungi has been reported and theophylline is the main conversion product in caffeine catabolism through demethylation [43, 44]. The influences of the isolated fungi on caffeine and theophylline metabolism were discussed in this paper. $A$. niger PET-1, A. pallidofulvus PET-3, A. sesamicola PET4 and P. mangini PET-5 increased caffeine content significantly through the inoculated fermentation. In contrast, during the aerobic fermentation of $A$. sydowii PET2 , caffeine content was decreased significantly $(p<0.05)$. At the end of the fermentation, about $83.88 \%$ of caffeine
(28.8 $\mathrm{mg} / \mathrm{g}$ of caffeine) was degraded, $93.18 \%$ of degraded caffeine was converted to theophylline, and $24.60 \pm 1.18$ $\mathrm{mg} / \mathrm{g}$ of theophylline was produced. Therefore, compared with other fungal strains, A. sydowii PET-2 was an effective strain converting caffeine to theophylline, which could be used in the production of theophylline through an aerobic fermentation.

Previous researches showed that $A$. sydowii has a high biotechnological potential $[45,46]$, it could produce monosaccharide [47] and indole alkaloids to restrain the proliferation of cells A549 [48]. The optimum conditions required for the production of theophylline such as moisture content, inoculation quantity and incubation temperature in aerobic fermentation were discussed in this study. The single factor analysis showed that the optimum conditions of theophylline production were 1) initial moisture content of $35 \%(\mathrm{w} / \mathrm{w}), 2)$ inoculation 

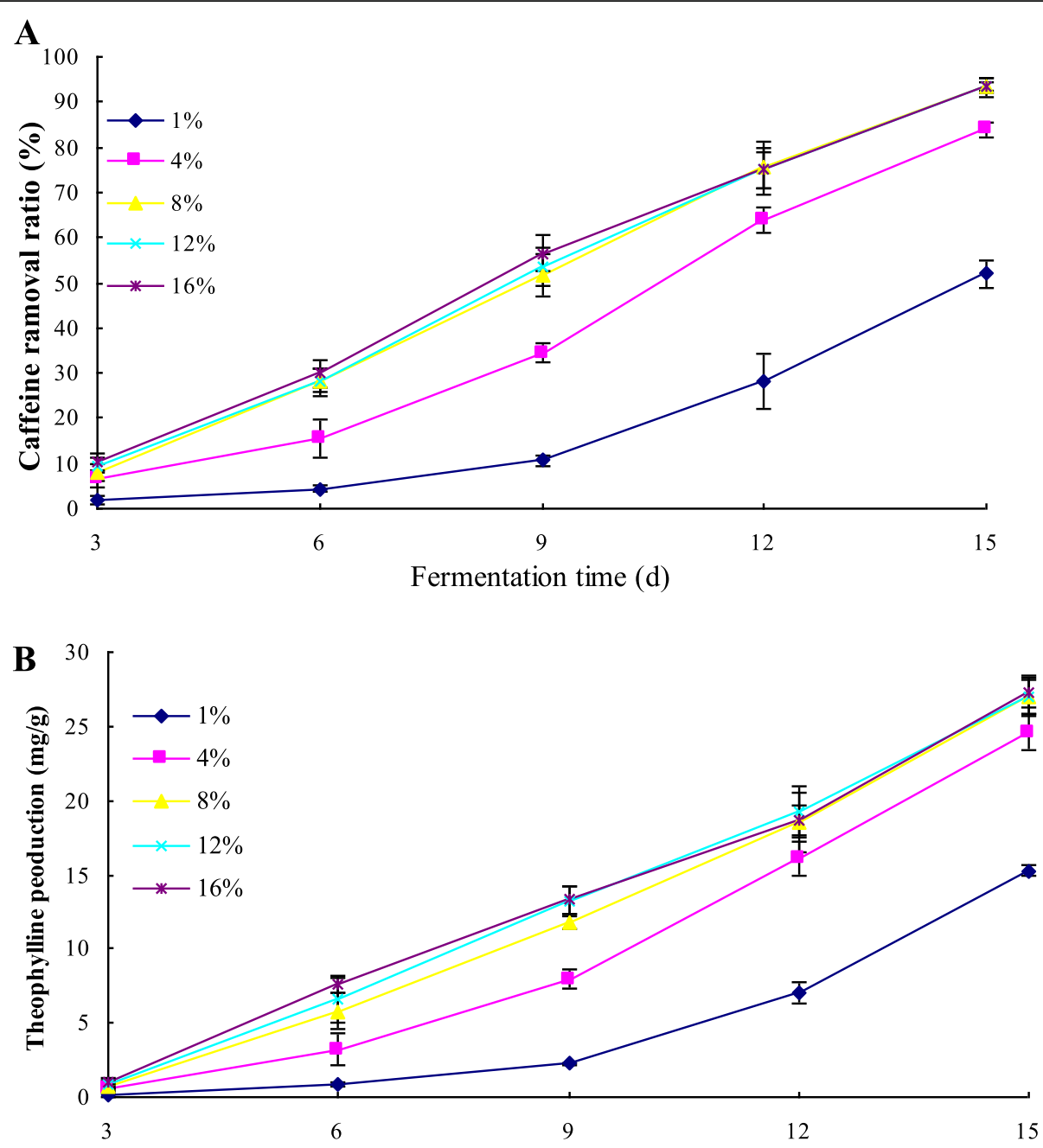

Fermentation time (d)

Fig. 5 Effect of inoculation level in an aerobic fermentation inoculated by A. sydowii PET-2 on caffeine degradation (a) and theophylline production (b). Data are presented as mean value \pm SD of three replications.Caffeine removal ratio $=\left(C_{\text {caffeine }, 0}-C_{\text {caffeine,t }}\right) / C_{\text {caffeine, }, 0^{*}} 100 \%$;

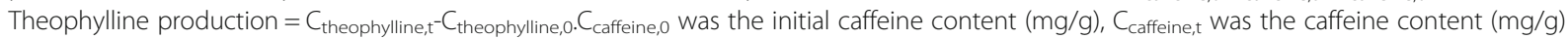
detected in the fermentation. $C_{\text {theophylline,t }}$ was the theophylline content $(\mathrm{mg} / \mathrm{g})$ detected in the fermentation, $C_{\text {theophylline, } 0}$ was the initial theophylline content $(\mathrm{mg} / \mathrm{g})$

quantity of $8 \%$, and 3) incubation temperature at $35^{\circ} \mathrm{C}$. The optimum conditions provided the relevant information for the conversion of caffeine to theophylline by $A$. sydowii PET-2.

\section{Conclusions}

Five fungal strains were isolated from the aerobic fermentation of pu-erh tea in natural condition. Among them, $A$. pallidofulvus, $A$. sesamicola and $P$. mangini were detected in pu-erh tea for the first time. Moreover, A. niger PET-1, A. pallidofulvus PET-3, A. sesamicola PET-4 and P. mangini PET-5 could increase caffeine content and had no significant impact on theophylline content. A. sydowii PET-2 was an effective strain converting caffeine to theophylline, which could be used for theophylline production. In addition, the optimum conditions of theophylline production in A. sydowii PET-2 aerobic fermentation were identified in this study, which provides the suggestions for the application of $A$. sydowii in theophylline production.

\section{Methods}

Material and reagents

Sun-dried green tea leaves (C. sinensis var. assamica) with moisture content $6.25 \%$ by weight were obtained from Yunnan province, China. SP fungal DNA kit, DNA marker, polymerase chain reaction (PCR) spread reagent, primers: ITS1 (5'-TCCGTAGGTGAACCTGCGG-3') and ITS4 (5`-TCCTCCGCTTATTGATAGC-3`); Bt2a (5`-GGTAA 

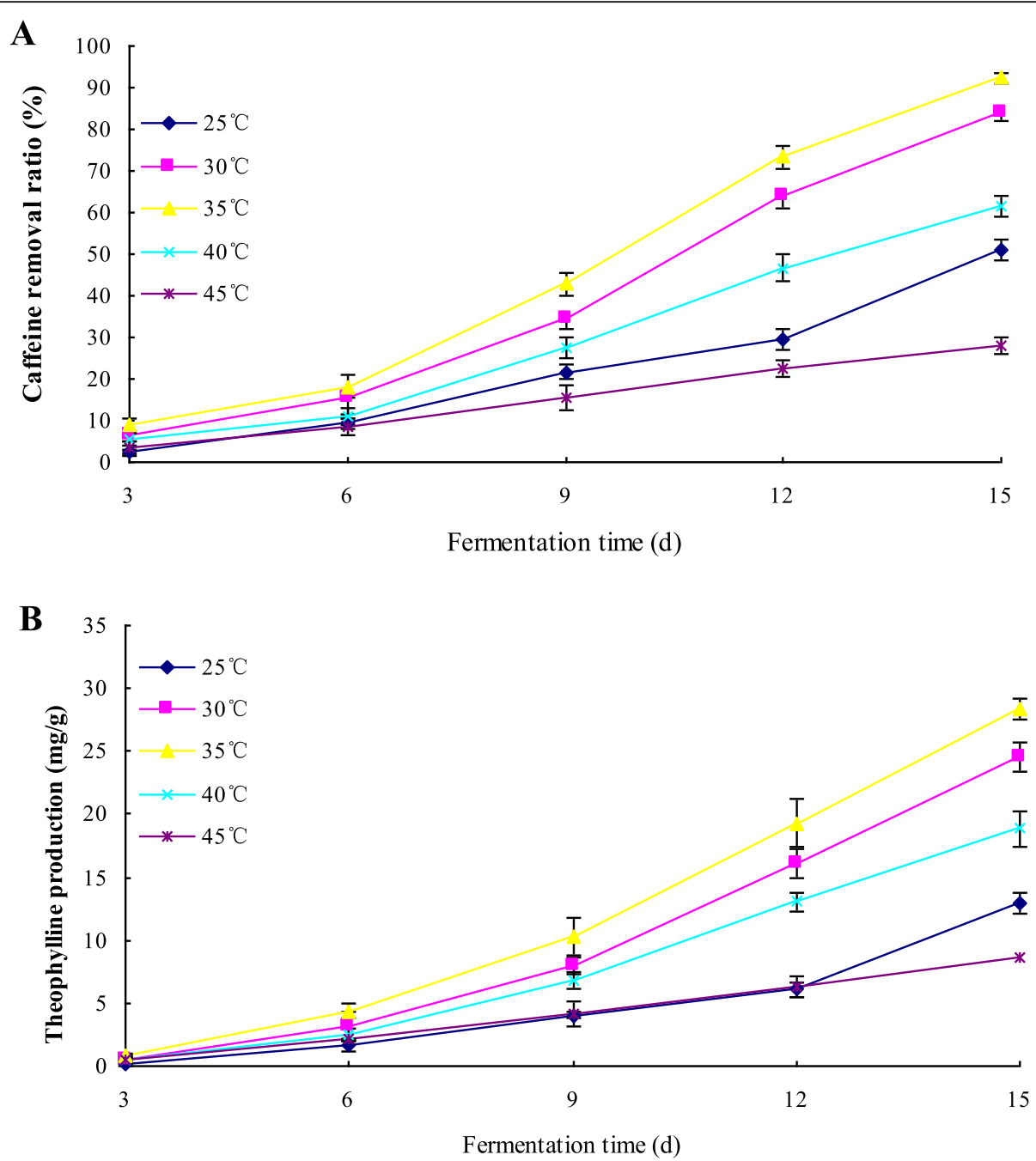

Fig. 6 Effect of incubation temperature in an aerobic fermentation inoculated by A. sydowii PET-2 on caffeine degradation (a) and theophylline production (b). Data are presented as mean value \pm SD of three replications. Caffeine removal ratio $=\left(C_{\text {caffeine }, 0-}-C_{\text {caffeine, }, t}\right) / C_{\text {caffeine }, 0}{ }^{*} 100 \%$; Theophylline production $=C_{\text {theophylline, }}{ }^{-} C_{\text {theophylline, }, 0} C_{\text {Caffeine,o }}$ was the initial caffeine content $(\mathrm{mg} / \mathrm{g}), C_{\text {caffeine,t }}$ was the caffeine content (mg/g) detected in the fermentation. $C_{\text {theophylline,t }}$ was the theophylline content $(\mathrm{mg} / \mathrm{g})$ detected in the fermentation, $C_{\text {theophylline,o }}$ was the initial theophylline content $(\mathrm{mg} / \mathrm{g})$

CCAAATCGGTGCTGCTTTC-3`) and Bt2b (5`-ACCCT CAGTGTAGTGACCCTTGGC-3'); and CF1L (5`-GCT GACTCGTTGACCGAAGAG-3`) and CF4 (5`-ATTTTT GCATCATGAGCTGAAC-3’) were purchased from Japan TaKaRa company. Acetonitrile and acetic acid for HPLC were purchased from Beijing Mreda Biotechnology Company, China.

\section{Aerobic and anaerobic fermentation at a natural condition}

The whole solid-state fermentation of pu-erh tea contains two phases: aerobic and anaerobic fermentation [31]. In this study, aerobic and anaerobic fermentation was carried out in Tea Processing Laboratory, College of Long Run $\mathrm{Pu}$-erh Tea, Yunnan Agricultural University, Kunming of
Yunnan province. About $400 \mathrm{~g}$ of sun-dried green tea leaves moistened with $220 \mathrm{~mL}$ distilled water to achieve an added moisture content of $35 \%(\mathrm{w} / \mathrm{w})$ and stored loosely in a 1000-mL Bunsen beaker for the aerobic fermentation [39]. The leaves were turned over before the collection of samples. In addition, another $400 \mathrm{~g}$ of sundried green tea leaves mixed with $220 \mathrm{~mL}$ distilled water were divided into six groups and each of them about 100$110 \mathrm{~g}$ was stored tightly in $150-\mathrm{mL}$ glass bottles with about $15 \mathrm{~mL}$ head-space. The bottles were completely sealed by lid and covered with gas-tight polyethylene film for the anaerobic fermentation. The fermentation was carried out at room temperature $\left(25 \pm 2{ }^{\circ} \mathrm{C}\right)$ based on the natural microbiota existing on the leaves [36]. The whole fermentation process continued for 15 days at a nature condition. 
Tea samples from aerobic and anaerobic fermentation were collected at day $0,3,6,9,12,15$, respectively. The samples were divided into two parts. One part was stored at $4{ }^{\circ} \mathrm{C}$ for further characterization and identification of fungi. Another part was dried at $80^{\circ} \mathrm{C}$ for $4 \mathrm{~h}$ for chemical components analysis. In the aerobic fermentation, caffeine content was declined significantly $(p<0.05)$ and theophylline content was increased significantly $(p<0.05)$. The samples from the aerobic fermentation were furthermore chose for the isolation and identification of the effective strain converting caffeine to theophylline.

\section{Isolation and calculation of fungi}

Fermented samples would be used to isolate the fungi using potato dextrose agar (PDA) medium and they were counted by dilution-plating method [35]. The colony forming units (CFU) was calculated by per gram of sun-dried tea leaves after 2 days of cultivation at $30^{\circ} \mathrm{C}$.

\section{Fungal identification}

The target strains grew aerobically as pure cultures in 20 $\mathrm{mL}$ of Czapek Dox medium in $125 \mathrm{~mL}$ shake flasks at $30^{\circ} \mathrm{C}, 250 \mathrm{rpm}$, for $2 \mathrm{~d}$. The fresh cells were obtained by centrifugation at $1700 \mathrm{~g}$ for $5 \mathrm{~min}$ and freeze-dried at $80^{\circ} \mathrm{C}[39,40]$. DNA was extracted by using SP fungal DNA kit. The fungal primers ITS1 and ITS4, Bt2a and Bt2b, and CF1L and CF4 were used in the PCR to amplify the ITS, $\beta$-tubulin and Calmodulin regions, respectively $[31,32,39]$. The final volume of $50 \mu \mathrm{L}, 1.0 \mu \mathrm{L}$ of containing template DNA, $5 \mu \mathrm{L}$ of $10 \mathrm{x}$ buffer, $5 \mu \mathrm{L}$ of dNTPs $(2.5 \mathrm{mM}), 0.5 \mu \mathrm{L}$ of Taq polymerase, $1.0 \mu \mathrm{L}(10 \mu \mathrm{M})$ of each primer, and $36.5 \mu \mathrm{L}$ of sterile distilled water were used to implement amplifications $[31,39]$. The PCR reaction procedure was as follows. Pre-degeneration at $95^{\circ} \mathrm{C}$ for $5 \mathrm{~min}$, degeneration at $94^{\circ} \mathrm{C}$ for $1 \mathrm{~min}$, annealing at $54^{\circ} \mathrm{C}$ for $1 \mathrm{~min}$, extension at $72^{\circ} \mathrm{C}$ for $1.5 \mathrm{~min}$, with $35 \mathrm{cy}$ cles, extension at $72^{\circ} \mathrm{C}$ for $10 \mathrm{~min}$ [33]. It was stored at $10^{\circ} \mathrm{C}$ in the end of the reaction process.

The PCR was produced in an ABI3730 automatic DNA sequencer (Applied Biosystems, USA) [20]. The received sequences were sent to Genbank of NCBI to seek similar sequences of type strain by using Blastn [35]. Multiple sequence alignment was carried out by using Clustal $\mathrm{X}$ for Windows. The evolution distance was calculated through a Kimura2-parameter of the MEGA 4.0 Soft.

\section{Aerobic fermentation inoculated by microbial isolate}

$400 \mathrm{~g}$ of sun-dried green tea leaves mixed with moderate distilled water was divided into six groups and each of them about $100-110 \mathrm{~g}$ was stored in a $150-\mathrm{mL}$ gas-permeable Tissue culture vessel for the aerobic fermentation [39]. Before the inoculation, high temperature sterilization at $121^{\circ} \mathrm{C}$ for 5 min was carried out to kill viable microorganisms with minimal damage in main functional components $[20,39]$.
Two loopfuls of isolated strains were transferred aseptically from a dish slant into $25 \mathrm{~mL}$ of sterile tea infusion in a $125 \mathrm{~mL}$ Erlenmeyer flask [20]. The flask was incubated aerobically at $30^{\circ} \mathrm{C}$ for $48 \mathrm{~h}$ on the incubator shaker $(250$ $\mathrm{rpm}$ ) [39]. The cell density was adjusted to $1.0 \times 10^{7} \mathrm{CFU} /$ $\mathrm{mL}$ and the inoculum was stored at $4{ }^{\circ} \mathrm{C}$ for the inoculation. About $4 \mathrm{~mL}$ above noted inoculum was added into per $100 \mathrm{~g}$ of dry weight sterile sun-dried tea leaves to obtain an inoculation quantity of $4 \%$. The initial moisture content was $35 \%(\mathrm{w} / \mathrm{w})$. Sterilization treatment with the identical moisture content was carried out as the control group. The culture vessels were incubated in a constant temperature incubator at $30^{\circ} \mathrm{C}$. Tea samples of inoculated fermentation and sterilization treatment were collected at day $0,3,6,9,12,15$, respectively. Caffeine and theophylline contents were determined by HPLC.

\section{Optimization in aerobic fermentation of target strain}

Experiments were performed during 15 days in an aerobic solid-state fermentation inoculated by target strain to evaluate the conversion level of caffeine to theophylline. Effects of moisture content, inoculation quantity and incubation temperature on caffeine degradation and theophylline production were analyzed [45].

(1) Moisture content. A set of different moisture contents $(25,30,35,40$, and $45 \% \mathrm{w} / \mathrm{w}$, respectively) were built with given inoculation quantity of $4 \%$. The inoculated leaves were incubated in a constant temperature incubator at $30^{\circ} \mathrm{C}$ for $0,3,6,9,12$ and 15 days, respectively.

(2) Inoculation quantity. A set of different inoculation quantities $(1,4,8,12$, and $16 \%$, respectively) were built and inoculated into the mixed tea to reach the identical moisture content of $35 \%(\mathrm{w} / \mathrm{w})$. The inoculated leaves were incubated in a constant temperature incubator at $30^{\circ} \mathrm{C}$ for $0,3,6,9,12$ and 15 days, respectively.

(3) Incubation temperature. Sun-dried green tea leaves were moistened with distilled water to achieve the given moisture content of $35 \%(\mathrm{w} / \mathrm{w}) .4 \%$ of above noted inoculum was inoculated into the sterile tea leaves. The culture vessels were incubated in a constant temperature incubator at different incubation temperatures $\left(25,30,35,40\right.$, and $45^{\circ} \mathrm{C}$, respectively). Tea samples were collected at day $0,3,6,9$, 12,15 , respectively.

Caffeine and theophylline contents were determined by HPLC.

\section{Determination of caffeine and theophylline by HPLC}

In order to determine caffeine and theophylline contents, the tea samples were extracted by boiling water for 45 min. Caffeine and theophylline contents were determined 
by Agilent 1200 HPLC equipment using Agilent $\mathrm{C}_{18}$ Chromatogram column $(250 \mathrm{~mm} \times 4.6 \mathrm{~mm}, 5 \mu \mathrm{m})$ with solvent A (100\% acetonitrile) and solvent B (0.2\% v/v acetic acid water solution) as mobile phase [49]. The gradient was programmed as follows. The mobile phase (at 0 $\mathrm{min})$ consisted of $92 \%(\mathrm{v} / \mathrm{v})$ solvent A (100\% acetonitrile) and $8 \%(\mathrm{v} / \mathrm{v})$ solvent $\mathrm{B}(0.2 \% \mathrm{v} / \mathrm{v}$ acetic acid water solution). Solvent A was then decreased linearly to $69 \%(\mathrm{v} / \mathrm{v})$ at $50 \mathrm{~min}$, whereas solvent B was increased linearly to $31 \%$ $(\mathrm{v} / \mathrm{v})$ at $50 \mathrm{~min}$. The flow rate was $1.0 \mathrm{~mL} / \mathrm{min}$ and $10 \mu \mathrm{L}$ of extraction was injected. The column temperature set at $30^{\circ} \mathrm{C}$ and the monitored wavelength was $280 \mathrm{~nm}$.

\section{Statistical analysis}

Caffeine removal ratio, theophylline production, $\mathrm{Y}_{\text {theo- }}$ phylline/caffeine and conversion ratio were used to evaluate the capability of target strain conversing caffeine to theophylline.

Caffeine removal ratio (\%) was estimated as follow:

Caffeine removal ratio $=\left(C_{\text {caffeine }, 0}-C_{\text {caffeine, },}\right) / C_{\text {caffeine }, 0} * 100 \%$

Theophylline production $(\mathrm{mg} / \mathrm{g})$ was estimated as follow:

Theophylline production $=\mathrm{C}_{\text {theophylline, } \mathrm{t}}-\mathrm{C}_{\text {theophylline }, 0}$

$Y_{\text {theophylline/caffeine }}$ was the yield of theophylline on caffeine and estimated as follow:

$$
\mathrm{Y}_{\text {theophylline/caffeine }}=\left(\mathrm{C}_{\text {theophylline }, \mathrm{t}}-\mathrm{C}_{\text {theophylline }, 0}\right) /\left(\mathrm{C}_{\text {caffeine }, 0}-\mathrm{C}_{\text {caffeine, }, \mathrm{t}}\right)
$$

Conversion ratio (\%) was used to evaluate the conversion efficiency from caffeine to theophylline and estimated as follow:

$$
\begin{aligned}
\text { Conversion ratio }= & {\left[\left(\mathrm{C}_{\text {theophylline }, \mathrm{t}}-\mathrm{C}_{\text {theophylline }, 0}\right) / \mathrm{M}_{\text {theophylline }}\right] / } \\
& {\left[\left(\mathrm{C}_{\text {caffeine }, 0}-\mathrm{C}_{\text {caffeine }, \mathrm{t}}\right) / \mathrm{M}_{\text {caffeine }}\right] * 100 \% }
\end{aligned}
$$

In Eqs. (1), (3) and (4), $\mathrm{C}_{\text {caffeine, } 0}$ was the initial caffeine content $(\mathrm{mg} / \mathrm{g}), \mathrm{C}_{\text {caffeine, } \mathrm{t}}$ was the caffeine content $(\mathrm{mg} /$ g) detected in the fermentation.

In Eqs. (2), (3) and (4), $C_{\text {theophylline, } t}$ was the theophylline content $(\mathrm{mg} / \mathrm{g})$ detected in the fermentation, $\mathrm{C}_{\text {theo- }}$ phylline, o was the initial theophylline content $(\mathrm{mg} / \mathrm{g})$.

In Eq. (4), $M_{\text {theophylline was the molar mass of theo- }}$ phylline and $\mathrm{M}_{\text {caffeine }}$ was the molar mass of caffeine. In this paper, $\mathrm{M}_{\text {theophylline }}=180.16 \mathrm{~g} / \mathrm{mol}, \mathrm{M}_{\text {caffeine }}=194.19$ $\mathrm{g} / \mathrm{mol}$, respectively.

Due to the uncertainty of the natural conditions, the natural fermentation was one parallel experiment. But the fungi count, caffeine and theophylline contents in the natural fermentation were three independent tests to ensure the credibility. The inoculated fermentation and optimization in aerobic fermentation were three replications to obtain reliable results. The mean value and standard deviation (SD) of analytic was calculated using SPSS 20.0 for Windows. The significant differences $(p<$ $0.05)$ was analyzed using one-way analysis of variance (one-way ANOVA) by Duncan's multiple-range test.

\section{Supplementary information}

Supplementary information accompanies this paper at https://doi.org/10. 1186/s12866-019-1640-2.

Additional file 1 Figure S1. The received sequence of strain PET-1. Figure S2. The received sequence of strain PET-2. Figure S3. The received sequences of strain PET-3. Figure S4. The received sequences of strain PET-4. Figure S5. The received sequences of strain PET-5.

Additional file $\mathbf{2}$ Table S1. Changes of other main chemica compounds in the fermentation of $A$. sydowii PET-2.

\section{Abbreviations}

ANOVA: Analysis of variance; CFU: Colony forming units; COPD: Chronic obstructive pulmonary disease; dNTPs: deoxy-ribonucleoside triphosphates; HPLC: High performance liquid chromatography; ITS: Internal transcribed spacer; MEGA: Molecular evolutionary genetics analysis; NCBI: National Center for Biotechnology Information; PCR: Polymerase chain reaction; PDA: Potato dextrose agar; PET: Pu-erh tea; SD: Standard deviation; SPSS: Statistical product and service solutions

\section{Acknowledgements}

We thank Kunming Dapu Tea CO., LTD, and Yunnan University for their assistance in sample collection and fungal identification.

\section{Authors' contributions}

BXZ and CQM participated in research design and the statistical analysis. CQM, XYR, XHL and YW participated in the performance of the research. $B X Z, C Q M$ and $X Y R$ participated in the writing and revision of the paper. XT contributed to the writing and data analysis. All authors read and approved the final manuscript.

\section{Funding}

This work was supported by Modern Agricultural Tea Industry System of Yunnan Province, China (2017KJTX007), Modern Agricultural Industry Technology System of China (CARS-23) and National Natural Science Foundation of China (31560221). The funding bodies had no role in the design of the study, in data collection, analysis or interpretation, or in writing the manuscript.

\section{Availability of data and materials}

The data that support the findings of this study are available from the corresponding author upon reasonable request.

Ethics approval and consent to participate

Not applicable.

\section{Consent for publication}

Not applicable.

\section{Competing interests}

The authors declare that they have no competing interests.

\section{Author details}

${ }^{1}$ College of Long Run Pu-erh Tea, Yunnan Agricultural University, Kunming 650201, Yunnan, People's Republic of China. ${ }^{2}$ Henan Key Laboratory of Tea Comprehensive Utilization in South Henan, Xinyang Agriculture and Forestry 
University, Xinyang 464000, Henan, People's Republic of China. ${ }^{3}$ Liaocheng Senior Financial Vocational School, Liaocheng 252000, Shandong, People's Republic of China. ${ }^{4}$ State Key Laboratory of Tea Plant Biology and Utilization, Anhui Agricultural University, Hefei 230036, Anhui, People's Republic of China.

Received: 31 October 2018 Accepted: 14 November 2019

Published online: 26 November 2019

\section{References}

1. Algharrawi KH, Summers RM, Gopishetty S, Subramanian M. Direct conversion of theophylline to 3-methylxanthine by metabolically engineered E. coli. Microb Cell Factories. 2015;14:203-15.

2. Yu CL, Louie TM, Summers R, Kale Y, Gopishetty S, Subramanian M. Two distinct pathways for metabolism of theophylline and caffeine are coexpressed in Pseudomonas putida CBB5. J Bacteriol. 2009;191(14):4624-32.

3. Hakil M, Denis S, Gonzalez GV, Augur C. Degradation and product analysis of caffeine and related dimethyl xanthine by filamentous fungi. Enzym Microb Technol. 1998;22(5):355-9.

4. Mohapatra BR, Harris N, Nordin R, Mazumder A. Purification and characterization of a novel caffeine oxidase from Alcaligenes species. J Biotechnol. 2006;125(3):319-27.

5. Dash SS, Gummadi SN. Degradation kinetics of caffeine and related methylxanthines by induced cells of pseudomonas sp. Curr Microbiol. 2007; 55:56-60.

6. Nanjundaiah S, Mutturi S, Bhatt P. Modeling of caffeine degradation kinetics during cultivation of Fusarium solani using sucrose as co-substrate. Biochem Eng J. 2017;125:73-80.

7. Oduro MD, Ocloo A, Lowor ST, Bonney EY, Okine LK, Adamafio NA. Isolation and characterisation of theobromine-degrading filamentous fungi. Microbiol Res. 2018;206:16-24.

8. Mazzafera P, Olsson O, Sandberg G. Degradation of caffeine and related methyxanthines by Serratia marcescens isolated from soil under coffee cultivation. Microb Ecol. 1996;31(2):199-207.

9. Wang LY, Wei K, Jiang YW, Cheng H, Zhou J, He W, Zhang CC. Seasonal climate effects on flavanols and purine alkaloids of tea (Camellia sinensis L.). Eur Food Res Technol. 2011:233(6):1049-55.

10. Zhu YC, Luo YH, Wang PP, Zhao MY, Li L, Hu XS, Chen F. Simultaneous determination of free amino acids in pu-erh tea and their changes during fermentation. Food Chem. 2016;194:643-9.

11. Sari F, Velioglu YS. Changes in theanine and caffeine contents of black tea with different rolling methods and processing stages. Eur Food Res Technol. 2013;237(2):229-36.

12. Chen YS, Liu BL, Chang YN. Bioactivities and sensory evaluation of pu-erh teas made from three tea leaves in an improved pile fermentation process. J Biosci Bioeng. 2010;109(6):557-63.

13. Oh HW, Kim BC, Lee KH, Kim DY, Park DS, Park HM, Bae KS. Paenibacillus camelliae sp. nov., isolated from fermented leaves of Camellia sinensis. J Microbiol. 2008:46(5):530-4

14. Su XQ, Zhang GJ, Ma Y, Chen M, Chen SH, Duan SH, Wan JQ, Hashimoto F, Lv HP, Li JH, Lin Z, Zhao M. Isolation, identification, and biotransformation of teadenol a from solid sate fermentation of pu-erh tea and in vitro antioxidant activity. Appl Sci. 2016;6:161-73.

15. Zhang L, Li N, Ma ZZ, Tu PF. Comparison of the chemical constituents of aged pu-erh tea, ripened pu-erh tea, and other teas using HPLC-DAD-ESIMS $^{n}$. J Agric Food Chem. 2011;59(16):8754-60.

16. LV HP, Zhang YJ, Lin Z, Liang YR. Processing and chemical constituents of Pu-erh tea: a review. Food Res Int. 2013;53(2):608-18.

17. Wang D, Xiao R, Hu XT, Xu KL, Hou Y, Zhong Y, Meng J, Fan BL, Liu LG. Comparative safety evaluation of Chinese Pu-erh green tea extract and $\mathrm{Pu}$ erh black tea extract in Wistar rats. J Agric Food Chem. 2010;58(2):1350-8.

18. Wang D, Xu KL, Zhang Y, Luo X, Xiao R, Hou Y, Bao W, Yang W, Yan H, Yao $P$, Liu LG. Acute and subchronic oral toxicities of Pu-erh black tea extract in Sprague-Dawley rats. J Ethnopharmacol. 2011;134(1):156-64.

19. Wang $X G$, Wan $X C$, Hu SX, Pan $C Y$. Study on the increase mechanism of the caffeine content during the fermentation of tea with microorganisms. Food Chem. 2008;107(3):1086-91

20. Zhou BX, Ma CQ, Wang HZ, Xia T. Biodegradation of caffeine by whole cells of tea-derived fungi Aspergillues sydowii, Aspergillus niger and optimization for caffeine degradation. BMC Microbiol. 2018;18:53. https://doi.org/10.1186/ s12866-018-1194-8.
21. Ma YJ, Jiang DQ, Meng JX, Li MX, Zhao HH, Wang Y, Wang LQ. Theophylline: a review of population pharmacokinetic analyses. J Clin Pharm Ther. 2016;41(6):594-601.

22. Shan Z, Rong W, Yang D, Yao P, Xie J, Liu L. Intravenous and nebulized magnesium sulfate for treating acute asthma in adults and children: a systematic review and meta-analysis. Respir Med. 2013:107(3):321-30.

23. Ashihara $\mathrm{H}$, Crozier A. Biosynthesis and metabolism of caffeine and related purine alkaloids in plants. Adv Bot Res. 1999;30(8):117-205.

24. Way TD, Lin HY, Kuo DH, Tsai SJ, Shieh JC, Wu JC, Lee MR, Lin JK. Pu-erh tea attenuates hyperlipogenesis and induces hepatoma cells growth arrest through activating AMP-activated protein kinase (AMPK) in human HepG2 cells. J Agric Food Chem. 2009;57(12):5257-64.

25. Lee LK, Foo KY. Recent advances on the beneficial use and health implications of pu-erh tea. Food Res Int. 2013;53(2):619-28.

26. Su JJ, Wang XQ, Song WJ, Bai XL, Li CW. Reducing oxidative stress and hepatoprotective effect of water extracts from pu-erh tea on rats with highfat diet. Food Sci Human Wellness. 2016:5(4):199-206.

27. Deng YT, Lin-Shiau SY, Shyur LF, Lin JK. Pu-erh tea polysaccharides decrease blood sugar by inhibition of a-glucosidase activity in vitro and in mice. Food Funct. 2015;6(5):1539-46.

28. Nyambe-Silawwe $H$, Williamson G. Polyphenol- and fibre-rich dried fruits with green tea attenuate starch-derived postprandial blood glucose and insulin: a randomised, controlled, single-blind, cross-over intervention. Br J Nutr. 2016;116:443-50.

29. Lyu CY, Chen CY, Ge F, Liu DQ, Zhao SL, Chen D. A preliminary metagenomic study of puer tea during pile fermentation. J Sci Food Agric. 2013;93(13):3165-74.

30. Huang YY, Xiao XD, Cong L, Wu MY, Huang YJ, Yao YN. A fermented tea with high levels of gallic acid processed by anaerobic solid-state fermentation. LWT-Food Sci Technol. 2016;71:260-7.

31. Abe M, Takaoka N, Idemoto Y, Takagi C, Imai T, Nakasaki K. Characteristic fungi observed in the fermentation process for puer tea. Int J Food Microbiol. 2008;124(2):199-203.

32. Zhao ZJ, Tong HR, Zhou L, Wang EX, Liu QJ. Fungal colonization of pu-erh tea in Yunnan. J Food Saf. 2010;30(4):769-84.

33. Haas D, Pfeifer B, Reiterich C, Partenheimer R, Reck B, Buzina W. Identification and quantification of fungi and mycotoxins from pu-erh tea. Int J Food Microbiol. 2013;166(2):316-22.

34. Zhang W, Yang RJ, Fang WJ, Yan L, Lu J, Sheng J, Lv J. Characterization of thermophilic fungal community associated with pile fermentation of pu-erh tea. Int J Food Microbiol. 2016;227:29-33.

35. Wang QP, Peng CX, Gong JS. Effects of enzymatic action on the formation of theabrownin during solid state fermentation of Pu-erh tea. J Sci Food Agric. 2011;91(13):2412-8.

36. Zhao M, Zhang DL, Su XQ, Duan SM, Wan JQ, Yuan WX, Liu BY, Ma Y, Pan $\mathrm{YH}$. An integrated metagenomics/metaproteomics investigation of the microbial communities and enzymes in solid-state fermentation of pu-erh tea. Sci Rep. 2015:5:10117 http://www.nature.com/articles/srep10117.

37. Qin JH, Li N, Tu PF, Ma ZZ, Zhang L. Change in tea polyphenol and purine alkaloid composition during solid-state fungal fermentation of postfermented tea. J Agric Food Chem. 2012;60(5):1213-7.

38. Liang YR, Zhang LY, Lu JL. A study on chemical estimation of pu-erh tea quality. J Sci Food Agric. 2005;85(3):381-90.

39. Wang QP, Gong JS, Chisti Y, Sirisansaneeyakul S. Fungal isolates from a puerh type tea fermentation and their ability to convert tea polyphenols to theabrownins. J Food Sci. 2015:80(4):M809-17.

40. Zhao M, Xiao W, Ma Y, Sun TT, Yuan WX, Na T, Zhang DL, Wang YX, Li YL, Zhou HJ, Cui XD. Structure and dynamics of the bacterial communities in fermentation of the traditional Chinese post-fermented pu-erh tea revealed by 16S RNA gene clone library. World J Microbiol Biotechnol. 2013;29(10):1877-84

41. Zhao H, Zhang M, Zhao L, Ge YK, Sheng J, Shi W. Changes of constituents and activity to apoptosis and cell cycle during fermentation of tea. Int J Mol Sci. 2012:12(3):1862-75.

42. Xia ZZ, Ni YN, Kokot S. Simultaneous determination of caffeine, theophylline and theobromine in food samples by a kinetic spectrophotometric method. Food Chem. 2013;141(4):4087-93.

43. Gummdi SN, Bhavya B, Ashok N. Physiology, biochemistry and possible applications of microbial caffeine degradation. Appl Microbiol Biotechnol. 2012:93(2):545-54

44. Dash SS, Gummadi SN. Catabolic pathways and biotechnological applications of microbial caffeine degradation. Biotechnol Lett. 2006;28(24): 1993-2002. 
45. Alvarenga N, Birolli WG, Seleghim Mirna HR, Porto A. Biodegradation of methyl parathion by whole cells of marine-derived fungi Aspgillus sydowii and Penicillium decaturense. Chemosphere. 2014;117:47-52.

46. Matkar K, Chapla DK, Divecha J, Nighojkar A, Madamwar D. Production of cellulase by a newly isolated strain of $A$. sydowii and its optimization under submerged fermentation. Int Biodeterior Biodegradation. 2013;78:24-33.

47. He F, Sun YL, Liu KS, Zhang XY, Qian PY, Wang YF, Qi SH. Indole alkaloids from marine-derived fungus Aspergillus sydowii SCSIO00305. J Antibiot. 2012; 65(2):109-11.

48. Song XQ, Zhang X, Han QJ, Li XB, Li G, Li RJ, Jiao Y, Zhou JC, Lou HX. Xanthone derivatives from Aspergillus sydowii,an endophytic fungus from the liverwort Scapania ciliate S. Lac and their immunosuppressive activities. Phytochem Lett. 2013;6(3):318-21.

49. Tan HP, Xu WP, Zhao AP, Zhao LL, Liu MD, Tan FY, Zou Y, Wang YJ. Determination of catechins and purine alkaloids in tea by high performance liquid chromatography. Anal Lett. 2012;45(17):2530-7.

\section{Publisher's Note}

Springer Nature remains neutral with regard to jurisdictional claims in published maps and institutional affiliations.

Ready to submit your research? Choose BMC and benefit from:

- fast, convenient online submission

- thorough peer review by experienced researchers in your field

- rapid publication on acceptance

- support for research data, including large and complex data types

- gold Open Access which fosters wider collaboration and increased citations

- maximum visibility for your research: over $100 \mathrm{M}$ website views per year

At $\mathrm{BMC}$, research is always in progress.

Learn more biomedcentral.com/submissions 